\title{
Engineering/Technology Talent Development on the College Campus
}

\author{
C. P. Ravikumar ${ }^{1}$
}

Received: 30 October 2020 / Accepted: 19 November 2020 / Published online: 2 January 2021

(C) Indian National Academy of Engineering 2021

\begin{abstract}
Engineering technology is evolving rapidly in the Information Age, much faster than institutions of learning can upgrade their programs and syllabi. India has developed more engineering programs that dwell on mathematical analysis, theory and an understanding of the science rather than engineering technology programs which focus on application of science to solve real-world problems. Industries rely on innovation which is all about making incremental modifications to existing solutions with the intention of adding value or improving the efficiency. Thus there is a fundamental disconnect in the expectation of industry from graduating students and the focus of engineering programs. In this paper, we will consider the aspect of industry-readiness of graduating engineers, focusing on three areas of engineering, namely, electronics and communication engineering, Electrical Engineering, and computer science. The objective of the paper is to identify the gaps and suggest ways to fill this gap.
\end{abstract}

Keywords Engineering education in India $\cdot$ Industry readiness $\cdot$ Technical talent development $\cdot$ Employability

\section{Introduction}

Engineering and engineering technology are often used as synonymous terms and there is not much difference between undergraduate or graduate programs offered in the country in either discipline-employers do not particularly consider whether a student has a degree in Engineering or Technology. However, a majority of the employers who visit campuses for hiring may be looking for potential employees who can apply engineering principles. In other words, these employers are looking for students with a degree in technology. As identified by Accreditation Board for Engineering and Technology (ABET), engineering undergraduate programs include more mathematics and higher-level math and focus on theory as compared to technology programs. Technology programs focus on application. At the work place, "engineering graduates may be expected to spend their time planning, while engineering technology graduates spend their time making plans work (Wikipedia 2020a)." There is a fundamental disconnect in the demand and supply-a majority of engineering colleges in India offer degrees in

C. P. Ravikumar

ravikumar@ti.com

1 Texas Instruments, India, Bagmane Tech Park, CV Raman Nagar, Bangalore 560093, India engineering. GATE, which is considered a mandatory exam for both engineering and technology programs in the country is called Graduate Aptitude Test in Engineering. Students who enter an undergraduate program in engineering spend about a third of their time studying mathematics, physics, and chemistry. Most colleges employ lecturers with a degree in mathematics, physics or chemistry to teach these courses; these teachers are rarely able to connect the principles being taught in the class with their engineering applications. An example is the treatment given to solution of differential equations; a student of electronics, communications, electrical engineering and computer science rarely require the techniques that are taught for solving second-order equations. I cannot recall a good example of second order equation with variable coefficients or an excitation other than DC or sinusoidal; yet, text book examples in mathematics tend to be unnecessarily complex and distract the student from the main purpose. As a matter of fact, the response of an RLC circuit to a sinusoidal excitation is an excellent example, but mathematical text books do not consider such examples, probably because the intention is to avoid examples from any one particular branch of engineering. Thus, when teaching circuit analysis, the instructor will likely repeat the mathematics behind solution of a second-order linear differential equation with constant coefficients. 
Even when text books carry excellent examples on applications, they are left out from the syllabus. A good example of this is linear algebra-while numerous text books have been written to emphasize the applications of linear algebra, students are rarely exposed to the applications. Modern text books emphasize on the use of computer software tools such as MATLAB to solve problems, but colleges overlook this suggestion and expect students to use calculators to solve numerical problems. As a result, the numerical problems are unrelated to any practical application. Even the courses pertaining to engineering disciplines include significant amount of mathematical analysis. As noted earlier, engineering teachers end up repeating mathematical concepts such as Fourier analysis, Laplace/Fourier Transform, probability theory, and poles and zeroes of a complex function. The same can be said of engineering chemistry and physics. There is merit in redesigning the curriculum to include the math, physics and chemistry on an "as needed" basis in the core courses of engineering disciplines. Text book writers always include the mathematical concepts required for engineers as an integral part of the text to aid the teachers. Taking such an approach will free up significant amount of time in the first year of the engineering curriculum, which can be used to emphasize on concepts that are more relevant today, as discussed in later sections of this paper.

The topic of industry-readiness of graduating engineers has been discussed in numerous forums and I have organized many such panel discussions in various conferences. Often, these discussions turn into a blame game, where representatives of industry and academia begin to call out their expectations from the other and express their anguish that the other party is not doing enough towards industry readiness. In this paper, we will consider the disciplines of electronics and communication engineering (ECE), electrical engineering (EE) and computer science (CS) and consider what industry-readiness means in each of these disciplines. The sudden growth of the Information Technology (IT) sector in India in the 1990s, the subsequent growth in the number of multinational companies led to a skew in the demand for talent. Easier availability of jobs in the IT sector prompted engineering students from all disciplines to opt for these positions. This imbalance adversely impacted research and development $(R \& D)$ in a number of sectors.

A number of educational institutions began to consider closing down programs in branches other than CS or IT. Since students graduating from disciplines other than CS and IT were also getting placed in jobs related to IT, the college management questioned the investment in running programs other than CS and IT. Interestingly, CS and IT departments did not need much infrastructure, since most students could afford to have their own personal computers and began to use open source software tools. With an eye on jobs, students began to take elective courses related to CS and IT; as a result, electives offered by the home department faced a setback. Students who would otherwise have carried out projects in their major field of study began to look for projects in CS and IT. This left an impact on the research of faculty members.

Needless to say, it is myopic to dis-invest in other programs due to a boom in one sector. There are several predecessors to this phenomenon from where we can draw a lesson. In the 1980s, the arrival of the microprocessors, DSP, and microcontrollers triggered an unprecedented interest in digital electronics, so much so that analog electronics became marginalized. But in the 2010s, there was a revival of interest in analog semiconductors and the semiconductor companies found themselves in a dire situation looking for students who had a good background in analog integrated circuit design; in fact, most colleges had no or very few teachers to teach concepts in analog design. Companies had to invest significant amount in retraining students in analog design. A second example is the disappearance of courses such as power electronics and electronic measurements from the ECE curriculum. Formation of departments such as Electrical and Electronics and Electronics and Instrumentation may have resulted in a decision to remove such courses from ECE. In the past decade, there is a renewal of interest in power semiconductors thanks to integration of power management blocks in integrated circuits. Similarly, the emergence of the Internet of Things (IoT) has led to an increased usage of measurements and smart metering. IoT end devices are equipped with sensors that can measure medical signals, electrical power consumption, water flow in a pipe, speed of a car, and so on. Since power electronics and measurement techniques have been neglected in undergraduate and graduate curricula, companies find it hard to find engineers who have a strong background in these domains.

This paper is organized as follows. In "Expectations of Industry", we will begin by looking at the general expectations of industrial corporations from graduating engineers. In "Electronics and Communications Engineering", we will examine the growth of the Electronics and Telecommunication sector and consider the gap between industrial practices and the instructional curriculum that is in vogue in Indian institutions. We will do a similar exercise in "Electrical Engineering" for the field of Electrical Engineering and in "Computer Science" for the field of Computer Science. Discussions and some conclusions are presented in "Discussion and Conclusions".

\section{Expectations of Industry}

In this paper, I will only focus on industries related to electronics, electrical, and computer engineering. Every company that hires engineers will look for two kinds of skills 
from students-(1) technical skills and (2) soft skills. Unlike experienced engineers who are hired for a specific job and are expected to possess specific technical skills, college graduates are hired for a broad role and are expected to have foundational knowledge and aptitude for the role. Companies offer opportunities for technical development for the new hire to gain the right skills to perform a specific role. Technical development (TD) may take the form of training sessions led by an instructor or may take the form of on the $j o b$ training. The success of technical development opportunities offered by engineering colleges as well as the company is measured by how fast a new hire can ramp up to perform his/her job. There are differences that must be noted between TD opportunities offered in an academic setup versus those that are offered in a corporate setup. College courses are spread over a semester and the total duration of instruction of about $30-40 \mathrm{~h}$ is divided into classes that are an hour in duration. In contrast, company trainings are offered as crash courses which are 3-5 days in duration, with up to $8 \mathrm{~h}$ of instruction/lab time each day. Corporate technical trainings demand tenacity and concentration from participants. In the work from home situation enforced by the COVID19 pandemic, corporates have switched to on-demand and self-paced trainings which have eased the situation considerably. The self-paced trainings make use of a variety of techniques such as videos, self-evaluation quizzes, and product demos. Some virtual training platforms also offer the ability for participants to comment on content and share their own videos, demos, or comments with others. The expectation from corporate management is that a new hire will make use the learning opportunities and quickly master the tools and techniques required to perform his/her job.

A variety of soft skills are required for new hires to integrate themselves with the company as well as the specific team in which they will perform. It is important for a new hire to be a team player and work towards the success of the project. In a college setting, students are taught to be competitive. The only opportunity that a student gets to collaborate with peers meaningfully is in the final project which is often carried out by a group of students. Students must make use of this opportunity to learn team playing skills. One of the members of the project team must act as a project manager and be responsible for keeping the project on track. If a team member is not taking the project seriously or if two members of the team have an ego clash, the project manager must sort out the issues. The faculty supervisor of the project may play the role of a superior manager and encourage the team to practice project skills such as project planning, risk taking and management, project execution, project reviews and project reporting.

Work ethics are expected from all employees. Each organization clearly defines its own values and code of ethics. Plagiarism is a problem in academic institutions world-wide and there are incidents of plagiarism in reputed institutions. In technical conferences being held today, the technical program committee has the additional burden of running plagiarism checks. Students who do not understand the laws of copyright or intellectual property protection may consider it harmless to reproduce a figure from a published paper in their own thesis. If they continue this after they join a company, unpleasant outcomes are bound to occur. Copying ideas or data on which we do not have intellectual property rights (IPR) is a punishable crime and there are numerous examples in the corporate world of such incidents (New York Times 2020). It is desirable that colleges include a module on engineering ethics in their curriculum. It is not necessary to include a course to teach ethics; such concepts can also be taught through posters, videos or seminars.

Communicating with peers is an important skill. Gaps in communication can result in misunderstanding at the personal level and execution delays at the project level. Such gaps can arise when a professional either forgets to communicate or intentionally does not communicate an important piece of information. With the goal of achieving a good grade, a student may intentionally not communicate a bug or a limitation in the project. Similarly, a student may knowingly or unknowingly not report that A variety of communication media are available today, such as e-mail, voice calls, text messaging and social media groups. Due to the ease of electronic communication, it is often abused and often we have to deal with an overwhelming amount of communication. Both written and spoken communication skills are important. Communicating succinctly, unambiguously and effectively is a skill that must be developed in order to avoid communication gaps and to be heard above the din of spam. Mail filtering, sorting and filtering techniques can also help in reducing the mail clutter. It is also important to follow communication etiquette when conversing with colleagues, vendors and customers. In a multinational company, communication will cut across national borders. When communicating with colleagues from other countries, a professional must deal with foreign accents and idioms.

Presentation skills are important in every engineering role. One may be called on to present technology overviews, tutorials, project proposals, project plans, project updates, or "lessons learnt" from a project. A good presentation must take into account constraints such as the background of the audience and the allotted time. The presenter must address the questions from the audience and provide justifications. While making slides for presentation is an art by itself, in a corporate setup, it may become necessary to present slides prepared by a colleague.

Time management is a soft skill that all professionals must learn as early in their career as possible. Understanding the importance of tasks and scheduling them, using a calendar to guide our daily activities such as meetings 
and phone calls, the ability to schedule meetings, being punctual in meetings and responding to mails, avoiding activities that waste time-all these are important to achieve work-life balance. During COVID-19 pandemic, when many professionals are working from home, time management is even more important. Without a calendar to manage daily activities, employees will feel burnt out by work which transcends all barriers.

A value that most companies expect from their employees is curiosity. In a world that constantly seeks innovation to bring down cost, reduce power and improve performance parameters, engineers have to continually master new concepts and acquire new skills. New hardware platforms, new software tools, new programming languages and new paradigms are arriving on the scene more frequently than before. Without a sense of curiosity for new ideas, we can be left behind. The following dialogue between Alice and the Queen of Red Hearts in Alice in Wonderland is an allegory for what we witness in today's technological world.

"Well, in our country," said Alice, still panting a little, "you'd generally get to somewhere else-if you run very fast for a long time, as we've been doing." "A slow sort of country!" said the Queen. "Now, here, you see, it takes all the running you can do, to keep in the same place. If you want to get somewhere else, you must run at least twice as fast as that!"

There are numerous examples of companies that continued to do business as usual without concern for the changing consumer habits and were caught off-guard, leading to major losses or even bankruptcy. Kodak, a very successful company whose business model was to sell camera film and the chemicals required for developing pictures filed for bankruptcy in 2012 due to popularity of digital cameras and integration of cameras in mobile phones. Surprisingly, the first digital camera was developed in Kodak, but the company chose not to make digital cameras fearing that it will impact their film and chemical business. Nokia, which had a monopoly on the cell phone market, did not recognize the importance of a better user experience through third-party applications and a better operating system and ended up losing the market to competitors (Valuer 2019). In corporations, the word tunnel vision is used to describe the tendency to focus only on the job at hand and failing to see the big picture. Many new hires tend to become complacent in their initial role and do not recognize that breadth is as important as depth for growth in an organization. While companies can provide learning opportunities, it is equally important for engineers to make use of these opportunities.

\section{Electronics and Communications Engineering}

In the 1980s and 1990s, a large number of multinational semiconductor companies saw the opportunity of establishing R\&D facilities in India. This was because of the existence of good engineering colleges in India that produced engineering graduates with the right background for carrying out IC design and test activities. In the early days, semiconductor companies could not find enough talented engineers and resorted to poaching talent from one another. An industry-sponsored special M.Tech program on VLSI Design, Tools, and Technology (VDTT) was first instituted at IIT Delhi in the mid 1990s and I was part of the team that was responsible for its definition and execution for several years. Semiconductor industries offered higher scholarship and several perks to students who were selected in the program with the goal of attracting top talent. As the founder of an annual symposium called VLSI Design and Test (VDAT), I introduced VLSI Education Day as part of the symposium to provide a forum for teachers from engineering colleges to come together, present their work, learn from peers, and participate in discussions. Government of India set up a special manpower development project (SMDP) to scale up the production of graduates well versed in concepts of VLSI design and the use of professional CAD tools. In the past 20 years, a large number of colleges in India have set up M.Tech programs in VLSI design. Several training institutes have emerged to offer tool-based training in different aspects of VLSI. At present, semiconductor companies do not face the shortage of manpower in VLSI; ironically, we have an excess of underqualified manpower to select from. This problem has been created due to the rapid evolution of the field in VLSI, as explained below, and the inability of the M.Tech programs to upgrade their curricula.

Lack of a commercial IC foundry in India has been a point of discussion for several decades. Numerous attempts have been made by multiple players to bring a commercial foundry services similar to TSMC to India, but they have not met with success. Dependence on an external service provider can be a problem in the long run for national defense and space programs. China has invested heavily in setting up foundries, as it prepares to compete with the United States of America in high-tech industries such as defense, space, and supercomputers. Lack of an Indian foundry also limits the opportunities for employment to students who graduate with a Master's degree in VLSI, with specialization in device fabrication. In any semiconductor company, there is a need for engineers who are skilled in device physics and fabrication technology. Good knowledge of device physics and interconnects is 
essential in analog design. As a result, students who carry out projects in device physics may have to reskill themselves in areas such as analog design and testing. Lack of a fabrication in India is also a limiting factor for academic research. Researchers who wish to fabricate their designs often depend on satellite programs from European foundries; these services are expensive and time-consuming.

\section{Rapid Evolution of Semiconductors}

The first transistor was invented in 1947 at Bell Labs and since then there has been no looking back for the field of semiconductors, which has propelled itself forward through the invention of new devices and manufacturing technologies. Bipolar transistors, which became popular in the 1950s, was used in the creation of many analog and digital circuit blocks which found use in defense, space, and later in consumer applications. With the intention of miniaturization and improving the reliability of electronic circuits, especially in defense applications, there was a need to integrate both active devices and passive interconnect into the same "solidstate" platform. This dream was realized in 1958 by Jack Kilby. Integrated Circuits have since evolved continually and rapidly. An aggressive target was provided in 1965 by Gordon Moore who predicted that the device densities in integrated circuits will double every year. The semiconductor industry drove many innovations in manufacturing and design in order to keep this prediction true. The transistor sizes were scaled by a factor of $\frac{1}{\sqrt{2}}$ every year for over 30 years, bringing down the cost of integrated circuits, reducing their power dissipation, and improving their speed performance. However, in the 1990s, transistor scaling began to throw up many challenges. Interconnect delays became comparable or even larger than switching delays in transistors, making it difficult to design integrated circuits. Earlier, there was a clean separation between front end (compilation of circuit descriptions written in hardware description languages into gate-level descriptions and mapping the gates to cells in a cell-library) and backend (placement of the circuit components on a planar surface and interconnecting them using wires implemented in metal and polysilicon. Similarly, power density of large integrated circuits became excessive. The use of complementary MOS transistors was originally invented to reduce power dissipation of digital gates, but when the number of transistors is in hundreds of millions, even the static power dissipation is significant. As a result, techniques for reducing leakage power reduction in circuits were invented in the 1990s. The third major problem in design was that of variability of process parameters, temperature and operating voltage from one transistor to another in the same die. Statistical variation of parameters is natural in an IC that contains millions of transistors. It is a challenge for the semiconductor vendor to produce chips that do not show unacceptable amount of statistical deviation in performance parameters, despite the on-chip variation of process parameters, temperature and voltage.

When samples of a manufactured IC arrive, they are subject to various measurements for the purpose of characterizing the device. Before the product is manufactured on a mass scale, it is mandatory to validate if the IC's performance parameters are as per the specification. It is also important to test if Testing of manufactured integrated circuits is necessary to preserve the quality of the product by eliminating the defective ICs. If a defective part escapes the tests and gets used in an end application, it may result in a system malfunction and cause loss of life and/or property in applications such as automotive electronics and industrial electronics. The ability to tolerate a certain number of faults and still operate safely is desirable in such applications. In these applications, an IC must not fail in the field during its life-time. This is referred to as reliability of the IC. Temperature stress testing is used to accelerate the failure of an IC that may have reliability issues. Such tests are expensive and applying them to every manufactured part will cause a steep increase in the price of the product. Sampled testing is one solution to this problem. Another alternative is to continually test the device during its lifetime and estimate the remaining life of the device.

\section{Telecommunication}

Electrical/electronic telecommunication has also come a long way since the invention of the telegraph and the telephone. Interestingly, wireless communication has its roots in India; J.C. Bose explored millimeter wave communication in his experiments with carriers of $60 \mathrm{GHz}$ frequency and used semiconductor junction diodes to pick up radio waves about 125 years ago. Early electronic communication systems were based on vacuum tubes. Semiconductors were widely adopted by communication industry after the invention of the BJT and the development of the integrated circuits. Like Gordon Moore's law for device density in integrated circuits, a law stated by Phil Edholm (Wikipedia 2020b) predicts that the bandwidth of communication systems doubles every 18 months. Indeed, the rate of communicating information has grown from bits/second to terabits/second in accordance to Edholm's law thanks to semiconductor revolution. Initially, communication of information was through analog signals passing over wires; digital communication is a more reliable form of communication and wireless communication provides great flexibility.The ability to exchange multimedia information over long distances in real time is made possible by technologies such as communication satellites and long-distance underwater optical cables. Establishment of local area computer networks (LAN) allows computers in a 
room or a building to communicate one another, making collaboration and sharing of resources such as printers possible. Communication with computers in distant locations is possible with metropolitan area networks (MAN). All the world's circuit-switched telephones are integrated into a single public switched telephone network (PSTN) through a variety of communication media such as telephone lines, optical fibre cables, microwave links, submarine cables, etc. Similarly, the Internet connects virtually all the computer networks across the world today. Due to availability of high-speed networking, e-commerce became a reality. In the "clientserver" model, personal computers have turned into "clients" and computing, storage, e-mail etc. have become available as "services" from a "computing cloud"- - servers that may be located in some distant part of the world.

Virtually all services are now available on-line and we have become used to cashless transactions and paperless offices, especially during the COVID-19 pandemic. Thanks to sensors, electronic communication technologies and cloud-based computing, it is now possible to connect anything to the Internet and track its behavior. This concept is called Internet of Things (IoT) - e.g. an electronic doorbell can be on the Internet, allowing the owner of the house to find out who is at the door of the house and speak to the guest/intruder even when the owner is away from home. Devices which are equipped with sensors and can be connected to the Internet are often referred to as "smart" devices.

Signals such as voice, images etc. must be obtained through sensors and must be amplified and filtered to remove noise. Communication of information across long distances is prone to corruption by channel noise. Similarly, security of communication is an important consideration, since sensitive information such as passwords may be stolen. Since the number of users making use of communication channels grows continually, there is also the need to use the available bandwidth efficiently by making use of compression techniques. Both analog and digital signal processing are therefore essential part of communication engineering.

\section{ECE Education}

As explained in this section, the field of electronics and communication has grown vastly and has impacted every aspect of human life. In an undergraduate degree that spans 4 years, it is difficult to cover all aspects of electronics or communication engineering. There have been two schools of thought in building an undergraduate curriculum. In some IITs, the undergraduate program is called Electrical Engineering. Foundational topics are covered in the first two years and there is some scope for specialization in the third and fourth years. In many engineering colleges, there have been attempts to develop specialized programs in sub-areas such as telecommunication and embedded systems. There are numerous Masters' programs connected to electronics and communication engineering, such as telecommunication, VLSI, Robotics, Signal Processing, etc. The rate at which curriculum is revised and the rate at which technology is advancing are mismatched, resulting in the curriculum becoming outdated quickly. Having participated in many curriculum update meetings, I have noticed the resistance from college teachers in modifying existing courses. For example, in one revision of an M.Tech curriculum, the suggestion to introduce course on Design Verification was met with much suspicion since there were no text books on the topic at the time. Similarly, industry representatives who participate in curriculum revision meetings tend to provide inputs which are highly industry-specific and often difficult to implement. Lack of the right text books and lab infrastructure are also reasons for not updating the curriculum. In a University with hundreds of affiliated colleges, even small changes in curriculum may be difficult to make. Lack of faculty training is also a major contributor to the gap in what is taught and what is expected to be taught.

Almost any modern topic related to electronics or communication is multidisciplinary in nature. Curriculum revision committees may have to take a deeper look at the available number of $h$ and propose a set of courses that will provide the student the inspiration required to pursue a career in the area of specialization. Teachers can make use of the vast amount of free online resources to guide students in the right direction. We must persuade teachers and students to think outside the box of a "standard text book" and "solved problems."

\section{Electrical Engineering}

Historically, electrical engineering was about electrical power generation, transmission and its end usage in lighting, heating and running motors. Over the years, electrical engineering diversified considerably and electronics emerged as a subdomain. Electronics engineering further diversified and computer science and computer engineering emerged as its domains. Today, even computer science and engineering have diversified and subdomains such as AI (artificial intelligence), ML machine learning and big data analytics have been identified. Technologies such as embedded computing, sensors, AI, ML, and data analytics have added new dimensions to the field of electrical engineering. There is increased push to tap renewable energy sources rather than depend on thermal power and improvements in solar power harnessing has added a further dimension to electrical engineering.

Solar power plants can be small or large. Surplus power generated by a household solar plant can be used to feed an electrical grid. Smart meters allow consumers to track their 
electricity usage and the electrical supply company to collect data over a period of time and analyze this data. Analyzing usage data can help the supply company plan better, reduce misuse and theft, and introduce suitable tariffs. Consumers can similarly gain insight into their own usage of power and improve their own usage pattern to reduce cost.

Wireless charging has entered the commercial market and devices to charge mobile phones, laptops and other smart devices are available today. This is a growing market segment and standards are beginning to evolve. There are attempts to bring wireless charging to electric vehicles. Electrical vehicles and hybrid electrical vehicles can reduce the pollution considerably. We often hear the remark that modern cars require more electronics and electrical engineering than mechanical engineering to build them. Battery management in such vehicles is a major concern. The temperature and voltage level of the battery must be continuously monitored to avoid accidents and extend the battery life. WiFi connectivity in the car helps in monitoring the charging of the vehicle from the car owner's mobile phone. Building better batteries is also a research area in electrical engineering, since storing energy generated from alternate sources such as wind and solar energies is an important aspect.

The multidisciplinary nature of projects in Electrical Engineering can be daunting (Nordström et al. 2014). Collaboration between departments of Electrical Engineering, Computer Science, and Electronics is essential for success. It is widely accepted today that there is a dearth of well-qualified graduates with a strong interest in traditional subjects such as Power Engineering. Academic programs are unable to attract top-ranking students to such branches and special programs may be necessary to rebuild competence in these areas (Bell et al. 2012).

\section{Computer Science}

Historically, computer science departments were spun off from Electrical Engineering or Electronics Engineering departments. In the early days, computer science was mainly concerned with programming, computability and complexity, correctness of programs, development of efficient algorithms, data structures, analysis of algorithms and counting techniques. As computer architectures evolved, courses related to computer organization and architecture were introduced. Courses on Operating Systems and Systems Programming, including assemblers, linkers, loaders and compilers, were added. The earliest application of computers included scientific programming. As a result, Fortran was taught as a programming language. Availability of digital computers was not widespread and there was no concept of computer labs. Data processing emerged as the next big application, spinning a number of jobs for COBOL programmers and data entry operators. When computer networks evolved, it became traditional to offer a course on the topic. Other applications of computers, such as Computer Graphics, Artificial Intelligence, Expert Systems, and Realtime computing evolved.

Growth of information technology has had the biggest impact on the way computer science education has shaped in India. Across India, engineering colleges introduced undergraduate and graduate programs in computer science and engineering. Unfortunately, however, the observations from leaders of IT industry about the employability of graduating students is dismal. N.R. Narayana Murthy of Infosys has gone on record stating that about $80 \%$ of youngsters are not trained for any job (Zee News 2018). A company called "Aspiring Minds" that develops and conducts psychometric tests for potential employees has said "6214 engineering institutions (from India) which are enrolling 2.9 million students and releasing 1.5 million students into job market every year. Only 7 shows the number Indian graduating students with a major in Computer Science during 2006-2013, a time period during with hiring from IT companies was at its peak. We see that the number doubled in about 4 years, but the growth rate began to slow down after 2010 (AICTE 2020) (Table 1).

Despite availability of CS majors, many IT companies look for talent in non-CS departments such as ECE and EE. Lack of aptitude in the CS student is a major reason; often, students enter the CS program for reasons such as parental pressure and the prevalent notion about ease of finding jobs. Some students prefer CS over ECE and EE because CS courses have less mathematical content. With the announcement of revised educational policy by the Government of India, we are beginning to see mushrooming of businesses that claim to offer coding experience to students of 6th grade and above. In most state schools, there is not even a good text book for students who opt for Computer Science as a specialization. The same can be said for engineering colleges as well. Many technological universities mandate programs such as internships to improve the exposure of students to industrial practices. However, mushrooming of companies that offer internships and project opportunities for a fee has

Table 1 Computer science graduates in 2006-2013 period

\begin{tabular}{lll}
\hline Year & \# of Engineering Colleges & \# CS graduates \\
\hline $2006-2007$ & 1511 & 181,320 \\
$2007-2008$ & 1688 & 200,160 \\
$2008-2009$ & 2388 & 286,560 \\
$2009-2010$ & 2972 & 356,640 \\
$2010-2011$ & 3222 & 386,640 \\
$2011-2012$ & 3393 & 407,160 \\
$2012-2013$ & 3498 & 419,760 \\
\hline
\end{tabular}


defeated this purpose. Lack of rigor, outdated curriculum, lack of qualified teaching staff, lack of research programs, lack of faculty development programs and lack of skill-based education are some of the top reasons for a vast number of CS students not being able to find suitable jobs after graduating. When we look at companies that work in the IT sector, we get some insight into why engineering colleges do not invest in research programs or faculty development programs. Top hiring firms in CS are into IT services and not R\&D. These companies often provide their own extensive training programs, since they may recruit students from non-CS departments. Availability of ready answers through search engines to most common problems through sites such as Stack Overflow on the Internet adds to the lack of motivation from learners. Programming languages such as Python provide powerful data structures and operations and they are further enriched with libraries; as a result, it is rarely required for a programmer to know the "internals" of implementation, such as the use of "pointers" for implementing lists.

After machine learning, big data analytics, artificial intelligence and neural networks have gained popularity in the last few years, many institutions are beginning to introduce undergraduate programs in these areas. At present, premier institutions such as the Indian Institute of Science and several IITs have introduced such programs. However, it can be anticipated that soon a plethora of such programs will be offered by a large number of engineering colleges. The preparation in colleges for offering such programs is inadequate. While these areas are speculated to herald the next big wave of job placements for students, whether such is the case is still unclear.

\section{Discussion and Conclusions}

A look at the syllabus of Graduate Aptitude Test in Engineering (GATE), which is used as a yard stick to measure the readiness of engineers to undergo a Masters program shows that it has not been updated to reflect the research areas in Electrical Engineering, Electronics, or Computer Science. Engineering institutions with some autonomy or those that are deemed universities have some flexibility in modifying their engineering curriculum. However, other than introduction of some elective courses, we do not see many attempts to introduce new programs that will produce the kind of engineers that are needed in the years to come. Some IITs have introduced undergraduate and graduate programs in AI. A frequent complaint which is heard from engineering institution is the core industries do not recruit their graduates for performing core functionality. For example, MS and $\mathrm{Ph} . \mathrm{D}$. students who carry out research in specialized areas such as smart materials or nanotechnology may not find jobs in India. Some of them take up postdoctoral positions to continue their research. Others take up industry jobs that may have little to do with their specialization. At the same time, core industries often complain about losing talent to IT sector and the gap that exists between what they expect from graduating students and what colleges offer. This problem can be solved to some extent when industries initiate programs for special manpower development. We saw an example of the VLSI Design, Tools and Technology program that was started at IIT Delhi in the 1990s, whose success also led to a number of M.Tech programs in VLSI across the country as well as the special manpower development program (SMDP) in the area of VLSI by the Government of India. Texas Instruments initiated an MS program in Analog Design at IIT Madras to address the gap it perceived in the skill level of analog designers.

When a single company is unable to initiate such programs, the consortium model may be the solution. For example, companies in the area of semiconductors supported a research program at IIT Kharagpur for many years, which led to manpower development in specialized areas. An equally important step is the initiation of specialized conferences in India where research students can publish their work and find opportunities to network. The VLSI Design conference held annually in India since the 1990s started as a small event but has steadily grown into a prestigious event. I started the VLSI Design and Test Workshops in the 1990s and within a few years, it saw increased attendance and quality; the workshops were renamed VLSI Design and Test Symposium and this event continues to draw researchers from both academia and industry in large numbers. I had initiated a program called VLSI Education Day as part of this symposium to exclusively discuss topics in VLSI education and promote industry-academia interaction. In the recent past, the International Test Conference has been holding a ITC India, allowing Indian researchers to present their work in the areas of semiconductor testing and validation. When I was the secretary of the VLSI Society of India, I was able to conduct highly specialized workshops in areas such as Design Verification, Memory Design and Test, Signal Integrity, and so on. The trend that we see today is for colleges to conduct highly generic conferences on topics. These conferences tend to attract a very broad audience. Lack of rigor in the selection of papers and conducting the technical sessions has brought down the value of such conferences. These conferences will be valuable if they become specialized and are steered by a committee of experts.

The projects which students carry out as part of their course work are very important towards their learning provided they are executed with rigor and are taken seriously both by students and the teachers. Selecting projects that are relevant to industry can help students as well as faculty 0 . A number of colleges allow their students to spend 
6 months or more in an industry in an internship program. Industries view the internship program as a part of their staffing initiative; students who do well in the internship are hired. Those who did not well in their projects or those who did not display aptitude for engineering may not be hired, but benefit from the exposure to industrial practices. An objection to the internship model from academic institutes is that it takes away the opportunity from students to pursue academic projects that can lead to research publications. The internship program can be meaningful when the student has a member of the college faculty as a co-supervisor for the project along with a supervisor from the industry. The internship project can be a win-win proposition when all the three parties work in harmony and have common goals. The industry must clearly state rules about how the rights for any intellectual property that may be developed during the project will be shared. Colleges and industry must both appreciate the value that the other party brings. What the industry brings to the table are the access to commercial tools, collateral know-how, rigor in testing and availability of test data. What an engineering faculty brings to the table are the ability to provide an abstraction to the project and the ability to write a technical paper. Such collaborations are the need of the hour to infuse life into industry-academia interaction. The internship model is not scalable and industry must think of ways to encourage industry-relevant projects in colleges (Gol et al. 2001). Availability of open-source software tools and remote access to lab equipment has made such projects viable. Colleges can permit students from multiple departments to collaborate on such projects to improve their quality. Industries can do their due diligence by making benchmark data available to colleges, compiling a list of relevant projects, actively participating in "open house" events conducted by colleges, providing review comments on projects, rewarding good projects.

\section{References}

AICTE (2020) Growth of technical institutions in the country. https ://www.aicte-india.org/downloads/growth_technical_institutio ns_310514.pdf
Bell KRW, Fenton B, Griffiths H, Pal BC, McDonald JR (2012) Attracting graduates to power engineering in the UK: successful university and industry collaboration. IEEE Trans Power Syst 27(1):450-457. https://doi.org/10.1109/TPWRS.2011.2163323

Gol O, Nafalski A, McDermott K (2001) The role of industry-inspired projects in engineering education. In: 31st Annual Frontiers in Education Conference. Impact on Engineering and Science Education. Conference Proceedings (Cat. No.01CH37193), Reno, NV, USA, 2001, pp. F3E-1,https://doi.org/10.1109/FIE.2001.963745

New York Times (2020) Star technologist who crossed google sentenced to 18 months in prison

Nordström L, Zhu K, Wu Y (2014) A multi-disciplinary course portfolio on computer applications in power systems. IEEE Trans Power Syst 29(4):1919-1927. https://doi.org/10.1109/TPWRS.

Ravikumar CP (2016) Industry's expectations from graduating engineers. In: Invited Presentation at Engineers' Conclave organized by IIT Madras, Sep 2016, Chennai, India

Ravikumar CP (2016) Systems perspective in curriculum, invited presentation at INCOSE academic forum. PES University, Bangalore

Ravikumar CP (2018) It's a smart world, after all. In: International Conference on Networking, Embedded and Wireless Systems, (ICNEWS 2018), organized by B.M.S. College of Engineering, Bangalore

Ravikumar CP (2020) Industry 4.0 in engineering education. In: International Virtual Conference on Industry 4.0, organized by VIT, July, 2020, Vellore, India

Ravikumar CP (2020) Shifting focus from Circuits to Systems. In: ETCCSD, International virtual conference on emerging trends on challenges in circuits to system design, organized by Vellore institute of technology, Vellore, India

Ravikumar CP (2019) Computer science and engineering: What next? Invited Presentation at "Road to CSA 50" conference held by Department of Computer Science, Indian Institute of Science, Jan 4. Bangalore, India

Valuer (2019) 50 Examples of corporations that failed to innovate. https ://tinyurl.com/y3woworq

Wikipedia (2020a) Accreditation board for engineering and technology.http://en.wikipedia.org/wiki/Accreditation Board for Engineering and Technology

Wikipedia (2020b) Edholm's law. https://en.wikipedia.org/wiki/Edhol $\mathrm{m} \% 27 \mathrm{~s}$ law

Zee News (2018) Narayana Murthy says $80 \%$ Indian youngsters not properly trained for any job, blames faulty education system

Publisher's Note Springer Nature remains neutral with regard to jurisdictional claims in published maps and institutional affiliations. 